Published in final edited form as:

J Am Med Dir Assoc. 2013 June ; 14(6): 386-391. doi:10.1016/j.jamda.2013.02.018.

\title{
Sensor Technology to support Aging in Place
}

\author{
Marilyn J. Rantz, PhD, RN, FAAN [Professor], \\ Hospital Professor of Nursing, University of Missouri, Columbia, Missouri, 573-882-0258 \\ Marjorie Skubic, PhD [Professor], \\ Department of Electrical and Computer Engineering, College of Engineering \\ Steven J. Miller, MA [Research Associate], Colleen Galambos, PhD [Professor], \\ Department of Social Work, College of Human and Environmental Sciences \\ Greg Alexander, PhD, RN [Associate Professor], \\ Sinclair School of Nursing \\ James Keller, PhD [Professor], and \\ Department of Electrical and Computer Engineering, College of Engineering \\ Mihail Popescu, RN, PhD [Associate Professor] \\ Department of Health Management and Informatics, School of Medicine
}

Sinclair School of Nursing and Family and Community Medicine, School of Medicine, University

Marilyn J. Rantz: rantzm@missouri.edu

\section{Keywords}

Older Adults; Sensor Technology; Aging in Place

\begin{abstract}
As people age, they want to remain as active and independent as possible for as long as possible. They want to age at home, not in institutions like nursing homes ${ }^{1}$. According to a 2010 AARP survey, 88 percent of people over age 65 want to stay in their residence for as long as possible ${ }^{2}$. Technology has the potential to help people remain at home by monitoring their health status, detecting emergency situations such as debilitating falls, and notifying health care providers of potential changes in health status or emergency situations. Researchers at the University of Missouri (MU) are using sensor technology at TigerPlace (a senior housing complex that enables residents to Age in Place) to detect changes in health status of the residents, alert health care providers, and augment traditional healthcare. This article reviews the Aging in Place research, TigerPlace as a state sponsored Aging in Place site, and the sensor technology developed by MU to support Aging in Place.
\end{abstract}

\section{Background Aging in Place Research at MU}

Aging in Place is the ability to live in one's own home safety and independently regardless of age, income, or ability level ${ }^{3}$. The goal of Aging in Place is to enable older adults to live

\footnotetext{
(C) 2013 American Medical Directors Association. Published by Elsevier Inc. All rights reserved.

Conflict of Interest

There are no conflicts of interest, including grant/financial support, with any of the authors who contributed.

Publisher's Disclaimer: This is a PDF file of an unedited manuscript that has been accepted for publication. As a service to our customers we are providing this early version of the manuscript. The manuscript will undergo copyediting, typesetting, and review of the resulting proof before it is published in its final citable form. Please note that during the production process errors may be discovered which could affect the content, and all legal disclaimers that apply to the journal pertain.
} 
in the environment of their choice with supportive services through the end of life, not forcing relocation as care needs change. The typical trajectory for older adults is forced relocation through higher levels of care as their health and functional ability declines. As an alternative, Aging in Place coordinates the necessary services enabling a client to stay at home ${ }^{1}$.

To develop and test the Aging in Place concept, Sinclair Home Care, a Medicare and Medicaid certified home health agency, was created as a department in the MU Sinclair School of Nursing in 1999. The school of nursing received a \$2 Million grant from the Centers for Medicare and Medicaid Services (CMS) to establish the agency and evaluate the Aging in Place (AIP) model. The AIP model combines home care services with registered nurse (RN) care coordination. Care coordination is a key component of AIP. The RN care coordinator manages the client's care across all disciplines (nursing, medical, physical therapy, social work, hospice, and others) making sure the client receives the care needed to age in place.

The results of the initial CMS evaluation indicated that the clinical outcomes were better for community based care with RN care coordination when compared to people with similar case-mix in nursing homes ( $\mathrm{n}=78$ in both groups $)^{4}$. The clinical outcomes are also better for clients receiving community based care with $\mathrm{RN}$ care coordination $(\mathrm{n}=55)$ than those without $\mathrm{RN}$ care coordination $(\mathrm{n}=30)^{5}$. The evaluation demonstrated potential savings to the Medicare and Medicaid programs of an average of \$1,591.61 per month for the aging in place group $(n=39)$ compared to the nursing home group $(n=39)^{6}$ and a $\$ 686$ average monthly savings to Medicare cost in the community-based clients with RN care coordination $(\mathrm{n}=57)$ compare to clients without $\mathrm{RN}$ care coordination $(\mathrm{n}=80){ }^{7}$

\section{TigerPlace Partnership and Electronic Medical Record Foundation}

Based on these results, the MU Sinclair School of Nursing (SSON) partnered with Americare Systems Inc. to build the ideal housing environment to test the AIP model. The collaboration resulted in the construction of TigerPlace, a retirement community enabling and allowing residents to age in place through the end of life, in the comfort of their own private apartment, never having to move to get their changing care needs met. TigerPlace was built to nursing home standards, is licensed as an intermediate care facility (ICF) with waivers to operate as an AIP facility, and run as independent housing with care as needed. Americare Systems Inc. manages the facility and service operations. The Sinclair Home Care Aging in Place manages the care component. When residents move into TigerPlace they provide informed consent for the evaluation of AIP and use of their de-identified health information for evaluation and research.

At TigerPlace, Sinclair Home Care Aging in Place provides routine assessment, operates a wellness center 5 days per week, and offers social work services, exercise classes, other health promotion activities, veterinary services for residents' pets and connections to MU events. A registered nurse is on call 24 hours per day 7 days per week to triage emergency situations. At the wellness center, residents have their vital signs checked, receive assistance with medications, have minor problems assessed, and consult with a nurse regarding health issues. Residents may also pay privately or with private insurance (about a third of the TigerPlace residents use their long term care insurance) for home care services, such as assistance with activities of daily living, medication management, wound care, and assistance with personal care, like bathing and dressing. ${ }^{8}$

From the outset in 1999, Sinclair Home Care captured all care and services in an electronic health record (HER). The foresight was to support research and evaluation of AIP; this HER was initially used for TigerPlace, but with the development of sensor technologies to 
enhance AIP, it was quickly realized that new solutions were needed. A new HER was developed for TigerPlace to encompass all of the standardized assessments routinely used by Sinclair Home Care as well as links to the sensor data from the new technologies so staff could use the information in normal workflow. ${ }^{9}$ It was necessary to create a custom system to be able to incorporate sensor data in a way that is efficient and supports clinical decision making. ${ }^{8}$ There is currently no commercially available system with the ability to integrate the health and sensor data. If sensor technologies are to be widely accepted, EHRs must support clinical decision making in a very efficient way so physicians and nurses are not accessing multiple databases.

TigerPlace residents are typical older adults. There are 64 residents ranging in age from 66 to 98 (mean 87.19). There are 11 couples and the remaining residents are single. Most residents have at least one chronic disease including heart disease, diabetes, osteoarthritis, or early stage dementia. The residents take an average number of 12.5 medications; 8 residents use wheelchairs and 28 residents use walkers. Most residents ambulate with no assistance.

An evaluation of the first 4 years of the AIP program conducted at TigerPlace and another continuing care retirement community demonstrated significantly lower costs and improved outcomes for the AIP clients when compared to national data for nursing home and assisted living residents. The combined housing and care costs for residents who received private pay services beyond the standard AIP program and who qualified for nursing home placement did not approach nor exceed nursing home costs. The mental and physical health outcomes revealed the effectiveness of the AIP model on health restoration and maintaining independence. ${ }^{10}$

\section{Sensor Technology Overview}

From the conception of our vision for AIP in the mid-1990s, we wanted to develop technologies to support older adults and help them maintain independence. ${ }^{11} \mathrm{We}$ assembled a comprehensive multidisciplinary team that talked about how to approach technology development. Telehealth solutions were considered and continue to be, since telehealth has a history of use to deliver health care to individuals with chronic illness at home. Numerous studies and published overviews of telehealth research have concluded that telehealth has the potential to be an effective way to manage chronic illness, influence the behavior of patients, and possibly improve health outcomes ${ }^{12,13,14}$; however, several problems persist. ${ }^{15}$ First, telehealth requires the person to be connected to expensive telehealth equipment, which can be costly for long-term monitoring. Second, several studies have shown that compliance with telehealth programs decreases over time. ${ }^{13}$ This is especially problematic given that chronic diseases require continuous monitoring for the rest of the person's life. Third, readings such as blood pressure, oxygen saturation, and blood sugar, are usually measured only once a day. With advances in technology, there are better, more informative, efficient and cost-effective ways to continuously monitor people in their homes.

The Center for Eldercare and Rehabilitation Technology (CERT) at the College of Engineering at MU was established to investigate, develop, and evaluate technology to serve the needs of older adults and others with physical and cognitive challenges (eldertech.missouri.edu). The Center includes interdisciplinary faculty, students, and staff from nursing, computer engineering, computer science, health informatics, social work, physical therapy, and medicine. Faculty and staff from the CERT are testing new technologies at TigerPlace with the help of the residents and their families.

As an initial step, focus groups were held at TigerPlace to explore older adults' perceptions and expectations of technology. The participants had a positive attitude toward the sensor technology that could enhance their lives. However, all of the participants thought that 
cameras would be too invasive and would violate residents' privacy. They emphasized the need for the devices to be unobtrusive, reliable, user friendly, able to detect a range of emergencies, and require no or minimal action on the part of the user. ${ }^{16}$ In fall 2005, initial sensor networks were installed in apartments of consenting residents at TigerPlace; separate consent processes are used for the technology research and other research projects at TigerPlace. Since that time, members of the research team observe the reaction of the participant residents who live with the sensor networks and interview them on a regular basis. The results indicated that the residents first become familiar with the technology and then adjust to having sensors in their homes. The final phase is full integration of the technology into the residents' lives. They forget the technology is there because it does not interfere with their daily lives ${ }^{17}$ allowing for true monitoring of daily activities. Figure 1 is a diagram of the sensor network installed in apartments of residents at TigerPlace and components that are under development.

The sensor network includes (1) stove temperature, bed, chair, and motion sensors; (2) pulse-Doppler radar and Microsoft Kinect sensors which are being tested and developed; (3) the electronic health record; 4) an integration and data storage element to collect all of the data including feedback from the clinical users; (5) a detection and recognition component to analyze the data; (6) an alert manager to notify clinicians of potential problems; and (7) a secure web-based interface to display the data for the clinicians and researchers; the interface will support patients and their caregivers in the future.

Inexpensive passive infrared motion sensors detect presence in a room and infer specific activities; for example, a sensor located above the shower monitors bathing activity, and sensors installed in kitchen cabinets and the refrigerator imply food preparation activities. The stove temperature sensor monitors cooking activities and can be used to generate an alert if the stove has been left on too long by a forgetful resident. The bed sensor detects presence in bed and measures qualitative pulse, respiration, and restlessness while the resident sleeps. The current bed sensor is a pneumatic strip which lies on top of the mattress under the sheets. ${ }^{18}$ The bed sensor detects 3 levels of pulse (low, normal, high) and respiration (low, normal, high) and 4 levels of restlessness (low, normal, high, very high) by measuring the change in air pressure. The bed sensor may be installed in a chair if that is where the person typically sleeps or spends a lot of time.

A secure web-based interface was developed to display the sensor data in a format that health care providers find easy to use and interpret, readily available, and clinically relevant. ${ }^{8}$ The interface was developed and refined with input from nursing, medicine, social work, health informatics, and engineering. The user selects a resident and a date interval. The default date range is two weeks prior to the current date. The sensors are grouped by type: motion, bed restlessness, bed pulse, and bed respiration. Histograms are used to display motion and bed sensor events which are aggregated to a daily level. Users may drill down to see specific sensors or other time frames, such as day (6:00 am to 10:00 pm) or night (10:00 pm to 6:00 am). Figure 2 displays the user interface of the sensor display for health care providers and research staff.

Motion density maps are used to visually track activity levels (See Figure 3). The motion sensors generate events every 7 seconds if motion is detected. Densities are calculated as the number of sensors events per hour divided by that time in the apartment during the hour. Color is used to represent density (activity level) ranging from gray (50 events per hour) to blue (550 events per hour). Black indicates time out of the apartment. White denotes no activity. ${ }^{19}$ The web-based interface shows the density maps with hours on the vertical axis and days on the horizontal axis (see Figure 3) so activity patterns can be visualized or automatically tracked for pattern changes over time. ${ }^{19,20,21}$ Additional maps were created 
to track other activities. These include a "Time in Bed" map that visually displays when the resident is in bed. A map was also created to present bathroom visits (See Figure 4).

\section{Key Findings of TigerPlace Sensor Technology Research}

As of August 1, 2012, a total of 49 people have been monitored with the integrated sensor system. 24 people have been discharged (10 people died, 10 people moved to a nursing home, 1 moved to residential care, 1 moved in with her daughter, and 2 withdrew for personal reasons) and 25 people remain in the research program. The current participants range in age from 66 to 98 with an average age of 87.99. There are 9 men and 16 women including 3 couples. All of the participants signed MU IRB approved informed consent to participate.

In a retrospective case study analysis, changes in the density maps correspond to exacerbations of mental illnesses including depression and dementia as measured by standard health assessments (Geriatric Depression Scale, Mini-Mental State Exam, and the SF-12 Health Survey). The densities can be used to alert clinicians to changes in mental health status allowing for early interventions assisting residents to age in place. ${ }^{20,21}$

Alerts were created to notify health care providers of potential illness or functional decline so they could intervene earlier with treatments to improve health outcomes and functional independence. A retrospective analysis surrounding 104 significant health events such as falls, hospitalizations, and emergency room (ER) visits revealed that changes appeared in the sensor data approximately two weeks before the event. ${ }^{8}$ Based on these results, initial alert algorithms were developed and tested with historical data. The alerts were implemented and refined with input from nursing, social work, and medicine.

The alerts were tested in a one year pilot study. Alerts for the intervention participants were sent to health care providers via secure email so they could assess the participants and intervene as warranted to improve functional independence. Outcome measures of the Short Physical Performance Battery (SPPB) ${ }^{22}$; the GAITRIte mat (a portable walkway of sensors), which measures temporal and spatial parameters of gait; totals of significant health events such as falls, hospitalizations, and ER visits; and hand grip strength were collected at baseline and quarterly throughout the study. The intervention group $(\mathrm{N}=20)$ show significant improvements as compared with the control group $(\mathrm{N}=21)$ in SPPB gait speed score at quarter $2(\mathrm{p}=0.02)$, right hand grip strength at quarter $4(\mathrm{p}=0.05)$, and GAITRite functional ambulation profile score at quarter $2(\mathrm{p}=0.05){ }^{23}$

During the pilot study, the clinicians reported that they want a more accurate bed sensor which would provide quantitative measurements of pulse, respiration, and restlessness. A new hydraulic bed sensor is under development at MU; it is in the process of deployment in TigerPlace now and preliminary data is exciting with more precise measurements of restlessness, respiration, and pulse. ${ }^{24,25}$ The more precise measurements will facilitate more accurate clinical judgments based on the sensor data by clinicians.

Range controlled pulse Doppler radar units have been installed in 10 apartments of residents of TigerPlace as part of an Agency for Healthcare Quality (AHRQ) grant to detect actual falls and assess fall risk. The radar units can capture gait parameters such as velocity and step time which can be used to assess fall risk. ${ }^{26}$ Figure 5 is a display of the actual raw range control radar (RCR) data and a spectrogram that shows the red spikes of individual footsteps of an older adult participant as he/she walked toward and away from the radar sensor in the course of normal daily activities. Notice the lower left corner displays the automated velocity (feet per second) of the walking as well as the step time (cadence in steps per 
minute). These parameters are used to monitor for increasing or decreasing fall risk assessment.

In addition, in a National Science Foundation (NSF) grant, 10 Microsoft Kinect sensors have been deployed in the same apartments as the AHRQ study. The depth image (an image in which the value of each pixel contains information about its distance from the camera) from the Kinect is captured continuously. The depth image is processed to compute gait parameters of stride time, stride length, and velocity. These gait parameters were validated against the Vicon marker-based system in the laboratory and showed good agreement. ${ }^{27}$ Also, height is computed from the Kinect data. Height may be used to help differentiate people, allowing monitoring of individuals in multiple resident apartments. Radar and motion sensors provide limited information when more than one person (a couple) shares an apartment; Kinect helps solve this problem.

\section{The Future}

In the very near future, we envision the variety of unobtrusive, inexpensive, in-home sensors that are used and are under development in apartments of residents at TigerPlace to be widely available to elders, their families, and health care providers. Health care alerts from automated algorithms from the sensor data have been in real-time use every day at TigerPlace for over 2 years. These alerts provide clinical decision support to clinicians who work there, helping them make earlier assessments and detect illnesses or changes in chronic illnesses days and even weeks before people complain of not feeling well or "quite right". Early detection and early intervention frequently avoids the need for hospitalization or emergency room visits, when problems get to stages that require more aggressive intervention.

For nursing home residents, we envision the newly developed bed sensor will be especially helpful, providing much needed information for clinicians to use. With quantifiable data about heart rate, respirations, and restlessness while in bed, clinicians can detect early signs of illness much like we have done in TigerPlace. Early changes in congestive heart failure, hypoglycemia, pain, delirium, upper respiratory infections, pneumonia, and urinary tract infections are common clinical problems detected by clinicians doing assessments after receiving an automated alert of changes in sensor patterns for particular residents living in TigerPlace. ${ }^{23,28}$ With additional refinement and testing in nursing homes, detection and decision support for staff can be widely available for their use, we hope in the not too distant future.

For those older people living in the community, we see community-based care coordination with decision support from the sensor data from homes of older adults. With the help of care coordination by nurses and other health care providers, families and the older person can learn what is "normal" and what simple strategies they can do to improve their function to maintain that "normal" at home where they can remain independent as long as possible. Nursing homes, continuing care retirement communities, home health agencies, and primary care geriatric practices are particularly well-positioned to provide the community-based care coordination with sensor technology decision-support. Technology, coupled with carecoordination, has the potential to revolutionize the way older adults are "Aging in Place," providing a brighter future for all of us as we age.

\section{Acknowledgments}

This article is based on results of NINR, AHRQ, and NSF funded research, 1R21NR011197-02 NINR (Rantz, PI, 2009-2012); R01HS018477 AHRQ (Rantz, PI 2009-2013); IIS-0428420 NSF (Skubic, PI, 2004-2009);

IIS-0703692 NSF (Skubic PI, 2008-2011); and CNS-0931607 (Skubic, PI, 2009-2013). Results and conclusions are 
the responsibility of the researchers, and not the opinion of granting agencies. Authors gratefully acknowledge the residents and staff of TigerPlace who graciously participate in our technology development research and the students and other faculty of the Center for Eldercare and Rehabilitation Technology Research Team at the University of Missouri.

\section{References}

1. Marek K, Rantz MJ. Aging in place: A new model for long term care. Nurs Admin Q. 2000; 24(3): $1-11$.

2. AARP Research \& Strategic Analysis. Home and Community Preferences of the 45+ Population. Washington, DC: Nov. 2010 Available at http://www.aarp.org/home-garden/livable-communities/ info-11-2010/home-community-services-10.html [Accessed August 20, 2012]

3. Centers for Disease Control (CDC). [Accessed on August 20, 2012] Health Places Terminology. 2012. Available at http://www.cdc.gov/healthyplaces/terminology.htm

4. Marek K, Popejoy L, Petroski G, Mehr D, et al. Clinical outcomes of aging in place. Nurs Res. 2005; 54(3):202-211. [PubMed: 15897796]

5. Marek KD, Popejoy L, Petroski G, Rantz MJ. Nurse care coordination in community-based longterm care. J Nurs Scholarship. 2006; 38(1):80-86.

6. Marek KD, Stetzer F, Adams SJ, Popejoy LL, Rantz M. Aging in place versus nursing home care: Comparison of cost to Medicare and Medicaid. Res Gero Nurs. 2012; 5(2):123-129.

7. Marek KD, Adams SJ, Stetzer F, Popejoy L, et al. The relationship of community-based nurse care coordination to costs in the Medicare and Medicaid programs. Res Nurs Health. 2010; 33:235-242. [PubMed: 20499393]

8. Rantz MJ, Skubic M, Alexander G, Aud M, et al. Improving nurse care coordination with technology. Comput Informatics Nurs. 2010; 28(6):325-332.

9. Popescu, M.; Chronis, G.; Ohol, R.; Skubic, M.; Rantz, M. An Eldercare Electronic Health Record System for Predictive Health Assessment. Proceedings of the IEEE 13th International Conference on e-Health Networking, Applications and Services; Columbia, MO. June 13-15, 2011; p. 194-196.

10. Rantz MJ, Phillips L, Aud M, Marek KD, et al. Evaluation of aging in place model with home care services and registered nurse care coordination in senior housing. Nurs Outlook. 2011; 59(1):3746. [PubMed: 21256361]

11. Rantz MJ, Marek KD, Aud MA, Tyrer HW, et al. A technology and nursing collaboration to help older adults age in place. Nurs Outlook. 2005; 53(1):40-45. [PubMed: 15761399]

12. Meystre S. The current state of telemonitoring: A comment on the literature. Telemed e-Health. 2005; 11(1):63-69.

13. Pare G, Jaana M, Sicotte C. Systematic review of home telemonitoring for chronic diseases: The evidence base. JAMIA. 2007; 14(3):269-277. [PubMed: 17329725]

14. Park E-J. Telehealth technology in case/disease management. Lippincott's Case Management. 2006; 11(3):175-182.

15. Wade R, Shaw K, Cartwright C. Factors affecting provision of successful monitoring in home Telehealth. Gerontology. 2012; 58(4):371-377. [PubMed: 22261740]

16. Demiris G, Rantz MJ, Aud MA, Marek KD, et al. Older Adults' Attitudes Towards and Perceptions of 'Smarthome' Technologies: a Pilot Study. Med Infor Internet. 2004; 29(2):87-94.

17. Demiris G, Parker-Oliver D, Dickey G, Skubic M, Rantz M. Findings from a Participatory Evaluation of a Smart Home Application for Older Adults. Technol Health Care. 2008; 16:111118. [PubMed: 18487857]

18. Mack DC, Patrie JT, Suratt PM, Felder RA, Alwan M. Development and preliminary validation of heart rate and breathing rate detection using a passive, ballistocardiography-based sleep monitoring system. IEEE Trans Infor Technol Bio. Jan.2009 13:111-120.

19. Wang S, Skubic M, Zhu Y. Activity Density Map Visualization and Dis-similarity Comparison for Eldercare Monitoring. IEEE Trans on IT in Biomed. 2012; 16(4):607-614.

20. Galambos C, Skubic M, Wang S, Rantz M. Using density map visualization for early detection and management of depression and dementia. Gerontechnology. 2012; 11(2):273-274. 
21. Galambos C, Skubic M, Wang S, Rantz M. Management of dementia and depression utilizing inhome passive sensor data. Gerontechnology. 2013; 11(3):457-468.

22. Guralnik JM, Simonsick EM, Ferrucci L, Glynn RJ, et al. A short physical performance battery assessing lower extremity function: association with self-reported disability and prediction of mortality and nursing home admission. J Gerontology. 1994; 49(2):M85-94.

23. Rantz MJ, Skubic M, Koopman RJ, Alexander G, et al. Automated Technology to Speed Recognition of Signs of Illness in Older Adults. J Gero Nurs. 2012; 38(4):18-23.

24. Rosales, L.; Skubic, M.; Heise, D.; Devaney, MJ.; Schaumburg, M. Heartbeat Detection from a Hydraulic Bed Sensor Using a Clustering Approach. Paper presented at: 34th Annual International Conference of the IEEE Engineering in Medicine and Biology Society; August 28-September 1, 2012; San Diego CA.

25. Su, BY.; Ho, KC.; Skubic, M.; Rosales, L. Pulse Rate Estimation Using Hydraulic Bed Sensor. Paper presented at: 34th Annual International Conference of the IEEE Engineering in Medicine and Biology Society; August 28-September 1, 2012; San Diego CA.

26. Cuddihy, PE.; Yardibi, T.; Legenzoff, ZJ.; Liu, L., et al. Radar Walking Speed Measurements of Seniors in their Apartments: Technology for Fall Prevention. Paper presented at: 34th Annual International Conference of the IEEE Engineering in Medicine and Biology Society; August 28September 1, 2012; San Diego CA.

27. Stone, E.; Skubic, M. Passive In-Home Measurement of Stride-to-Stride Gait Variability Comparing Vision and Kinect Sensing. Proceedings of 33rd Annual International Conference of the IEEE Engineering in Medicine and Biology Society; Boston, MA. August 30-September 3, 2011; p. 6491-6494.

28. Skubic, M.; Rantz, M.; Miller, S.; Guevara, RD., et al. Non-Wearable In-Home Sensing for Early Detection of Health Changes. In: Schultz, R., editor. Quality of Life Technology Handbook. Boca Raton: CRC Press; 2012. p. 227-244. 


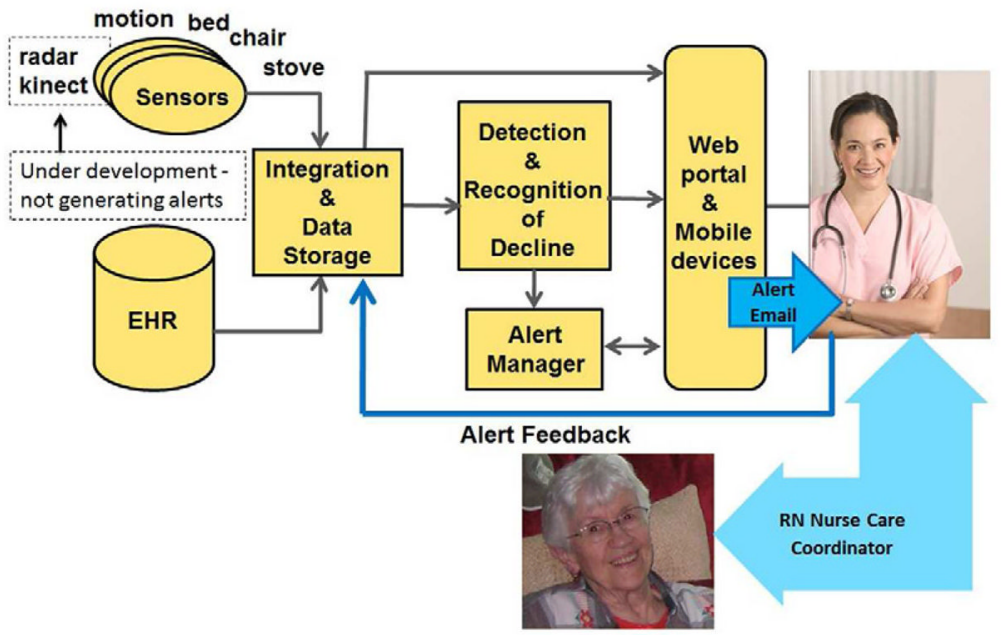

Figure 1.

Integrated Sensor Network under Development at TigerPlace 


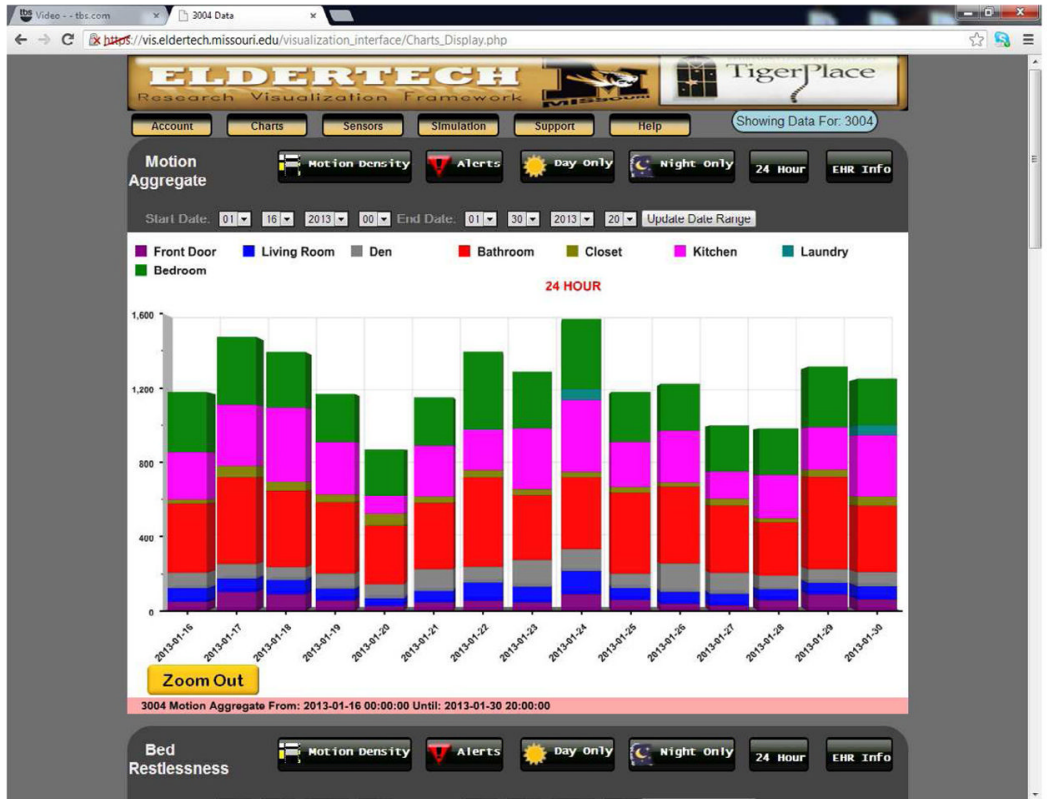

Figure 2.

Interface of the Sensor Display for Health Care Providers and Research Staff 


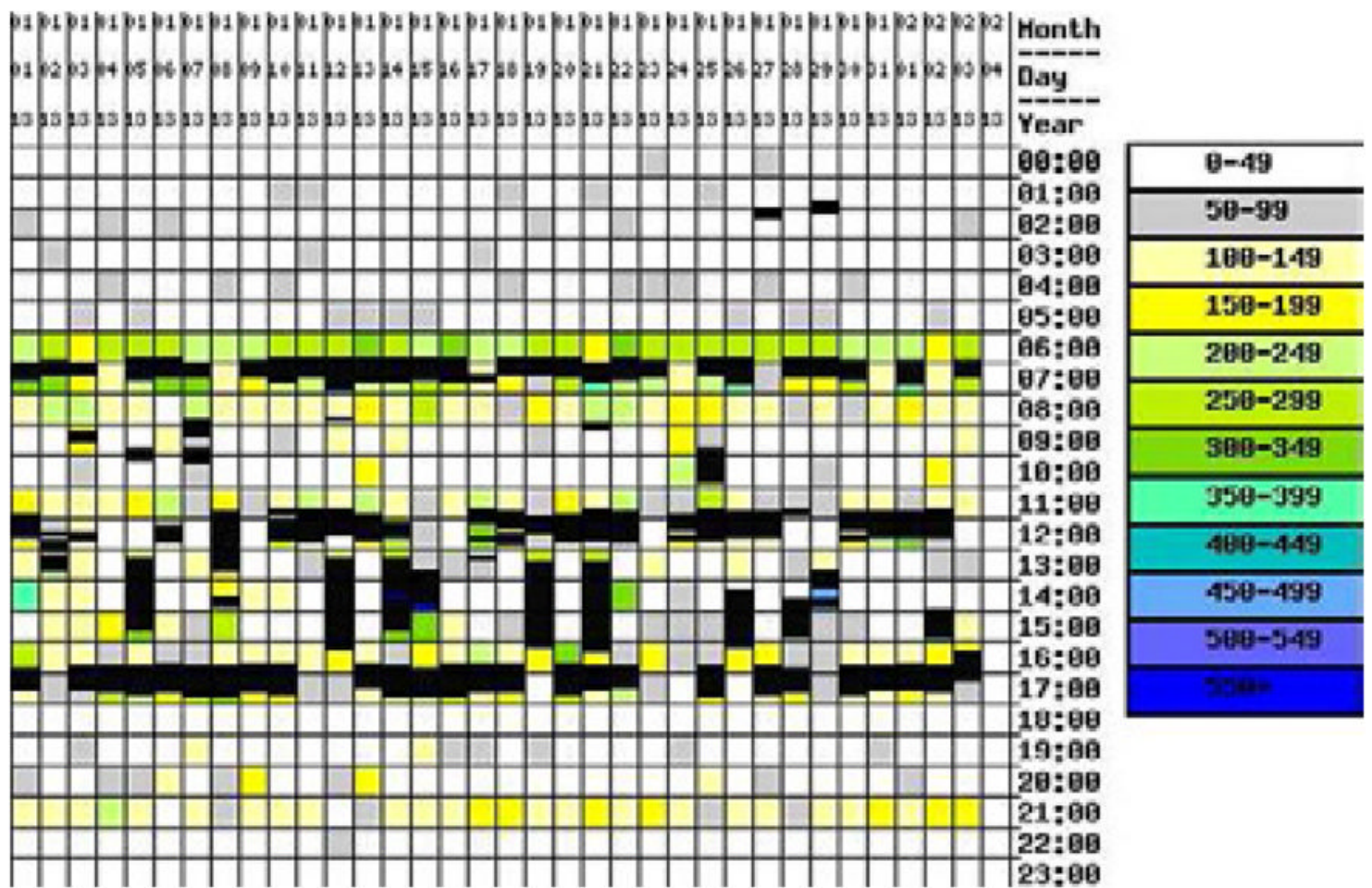

Figure 3.

Motion Density Map 


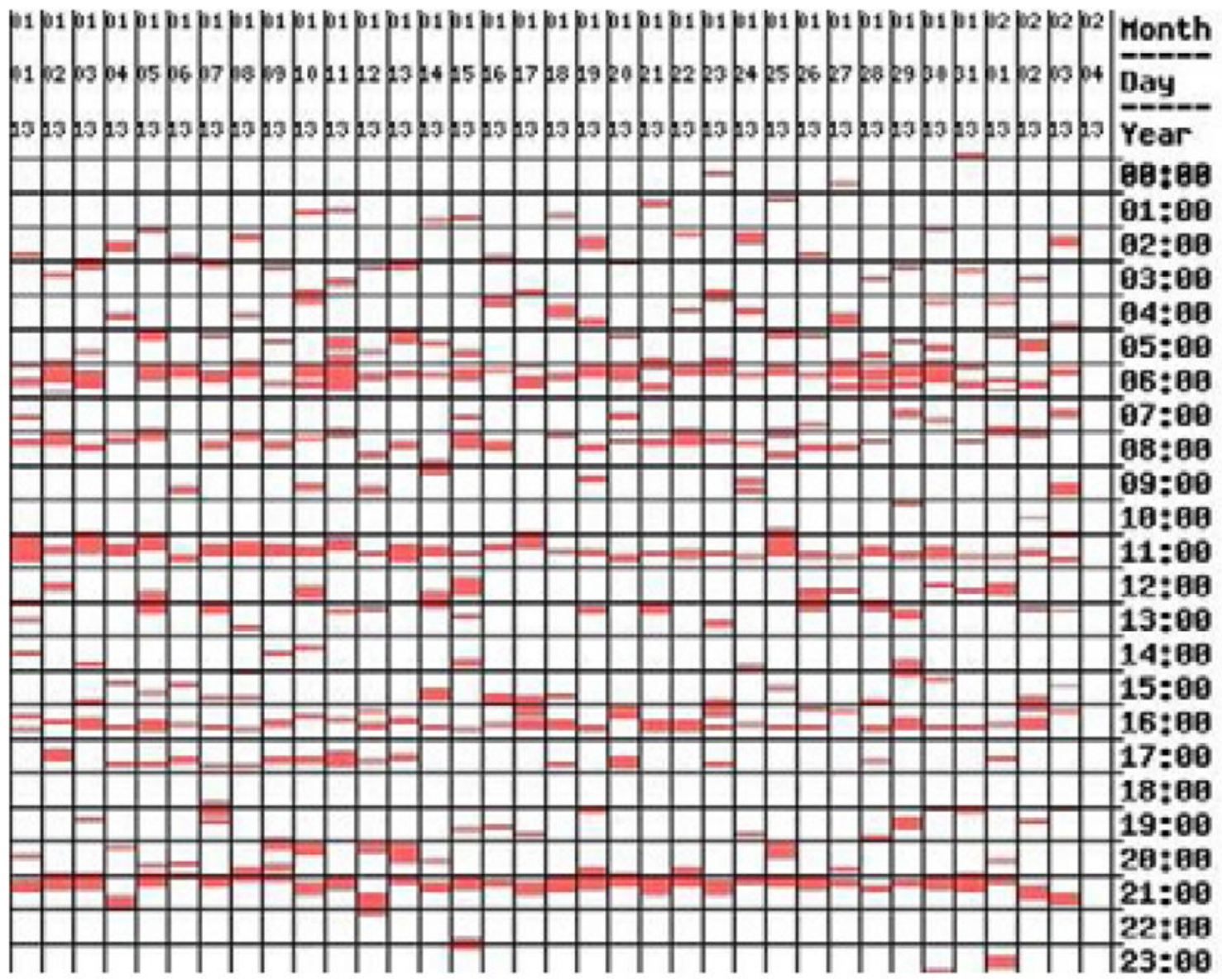

Figure 4.

Motion Density Map for Bathroom Visits 


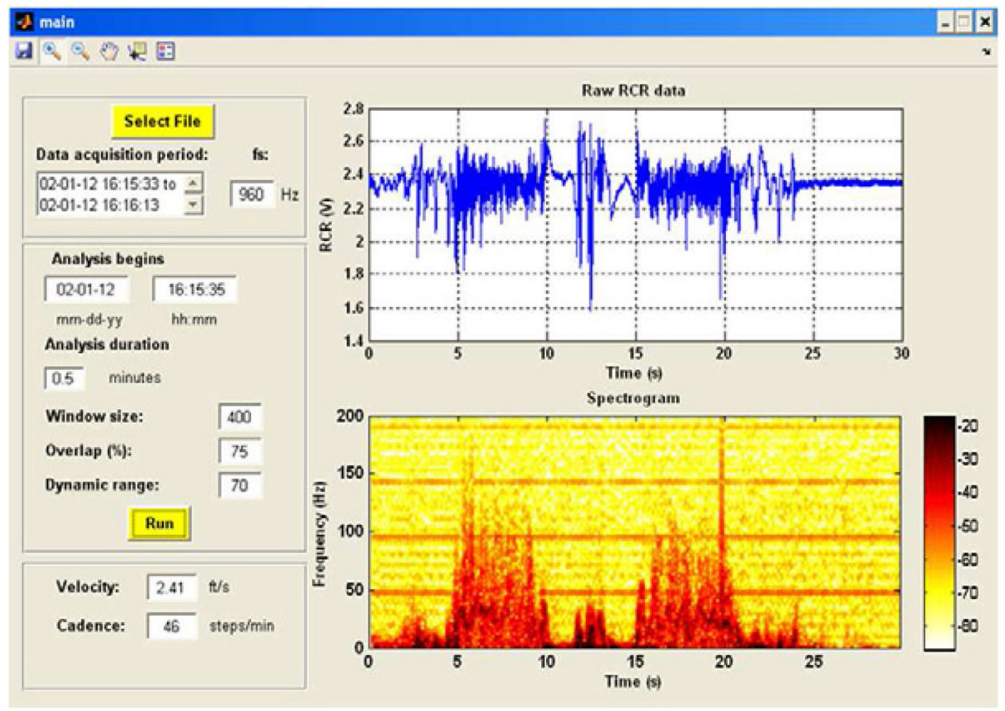

Figure 5.

Range Controlled Radar Raw Signal and Spectrogram with Automatic Processing of Velocity and Step Time 